\title{
The Origin of Sars-CoV-2: Why It Matters
}

\author{
Paolo Vineis ${ }^{1 *+}$ and Stefania Salmaso ${ }^{2,3+}$ \\ ' Department of Epidemiology and Biostastistics, Imperial College London, London, United Kingdom, ${ }^{2}$ stituto Superiore di \\ Sanità, Rome, Italy, ${ }^{3}$ Italian Society of Epidemiology, Rome, Italy
}

Keywords: SARS-CoV-2, Wuhan, bats, Mojian mine, COVID-19

\section{OPEN ACCESS}

Edited by:

Marc Jean Struelens,

Université Libre de Bruxelles, Belgium

Reviewed by:

Mathias Martins,

Cornell University, United States

Su Datt Lam,

National University of

Malaysia, Malaysia

*Correspondence:

Paolo Vineis

p.vineis@imperial.ac.uk

†These authors have contributed equally to this work

Specialty section:

This article was submitted to Infectious Diseases-Surveillance,

Prevention and Treatment, a section of the journal

Frontiers in Public Health

Received: 03 June 2021

Accepted: 11 August 2021

Published: 08 September 2021

Citation:

Vineis $P$ and Salmaso S (2021) The Origin of Sars-CoV-2: Why It Matters.

Front. Public Health 9:719914.

doi: 10.3389/fpubh.2021.719914
As Bloom et al. (1) have indicated in a letter to the Science magazine, clarity should be made about the origins of Sars-CoV-2, outside any political out-of-context use of limited scientific evidence. The accusations toward China, and specifically the Wuhan virology laboratory, have been based so far on little evidence and much political speculation. It is time to collect evidence, before making statements based on "likelihood" that the origin of the virus is "natural" (from bats) or not (from a laboratory). This was the message in Bloom and colleagues' letter, and in the accompanying, balanced, Editorial by Thorp (2). Why is it important to know? Not only to stop political speculations on both sides, but mainly to help science to reconstruct the causal chain and be able to predict next spillovers, either from laboratory accidents or from the wildlife. At stake there is not only the safety of laboratories that manipulate living organisms, but also a better understanding of future scenarios related to natural degradation and planetary overload. We need to know the impact of deforestation, animal farming, animal markets, etc. on the risk of spillovers, to be able to prevent them.

As reported by a paper published in Frontiers in Public Health in 2020 (3), commented upon more recently by Speciale (4), 6 workers in 2012 developed severe pneumonia with symptoms very similar to those of COVID-19. They worked in a copper mine in Mojiang, in the Yunnan province (China), to clean huge guano deposits left by bats. Samples were collected from the miners and from bats, and then analyzed for viruses at the Wuhan laboratory. In October 2020, Rahalkar and Bahulikar (3) proposed that the Mojiang mineshaft miners' illness could provide important clues to the origin of SARS-CoV-2. They suggested that there were striking similarities between the Mojiang pneumonia cases and COVID-19, and reported about a Master's thesis that concluded that the pneumonia in the miners was due to a SARS-like CoV from horseshoe bats. These conclusions were contradicted by researchers at the Wuhan Institute of Virology in a Nature paper (5), which did not find evidence of SARS-CoV infection among the workers. However, in the same paper phylogenetic analysis indicated that a coronavirus collected from bats in the cave and designated RaTG13 had a 96\% resemblance to SARS-CoV-2. Therefore, the case is still open.

There are several remaining questions about the Sars-CoV-2 pandemic but one of the most important is to understand how the virus that initiated the epidemic spread in Wuhan City and to identify the missing links between the viruses circulating in bat populations and the human virus. Different theories of accidental release from a lab and zoonotic spillover remain possible (1) and the currently available evidence does not allow us to draw a firm, straightforward conclusion. Part of the problem is that the controversy over the epidemic origin has become part of a political debate, while independent reliable research and evidence is needed as to whether SARS-CoV-2 came directly from bats or indirectly through intermediate hosts.

This story is only a small piece of a probably much larger
puzzle that involves wildlife and laboratories. There is certainly


a need to "document the veracity and provenance of data from which analyses are conducted and conclusions drawn so that analyses are reproducible by independent experts" as Bloom's letter indicates (1).

\section{REFERENCES}

1. Bloom JD, Chan YA, Baric RS, Bjorkman PJ, Cobey S, Deverman $\mathrm{BE}$, et al. Investigate the origins of COVID-19. Science. (2021) 372:694. doi: 10.1126/science.abj0016

2. Thorp HH. Continued Discussion on the Origin of COVID-19. Available online at: https://blogs.sciencemag.org/editors-blog/2021/05/13/continueddiscussion-on-the-origin- of-covid-19/

3. Rahalkar MC, Bahulikar RA. Lethal pneumonia cases in mojiang miners (2012) and the mineshaft could provide important clues to the origin of SARS-CoV-2. Front Public Health. (2020) 8:581569. doi: 10.3389/fpubh.2020.581569

4. Speciale A. Commentary: lethal pneumonia cases in mojiang miners (2012) and the mineshaft could provide important clues to the origin of SARS-CoV-2. Front Public Health. (2021) 9:702199. doi: 10.3389/fpubh.2021.702199

5. Zhou P, Yang XL, Wang XG, Hu B, Zhang L, Zhang W, et al. Addendum: a pneumonia outbreak associated with a new coronavirus of probable bat origin. Nature. (2020) 588:E6. doi: 10.1038/s41586-020-2951-z

\section{AUTHOR CONTRIBUTIONS}

All authors listed have made a substantial, direct and intellectual contribution to the work, and approved it for publication.

Conflict of Interest: The authors declare that the research was conducted in the absence of any commercial or financial relationships that could be construed as a potential conflict of interest.

Publisher's Note: All claims expressed in this article are solely those of the authors and do not necessarily represent those of their affiliated organizations, or those of the publisher, the editors and the reviewers. Any product that may be evaluated in this article, or claim that may be made by its manufacturer, is not guaranteed or endorsed by the publisher.

Copyright (c) 2021 Vineis and Salmaso. This is an open-access article distributed under the terms of the Creative Commons Attribution License (CC BY). The use, distribution or reproduction in other forums is permitted, provided the original author(s) and the copyright owner(s) are credited and that the original publication in this journal is cited, in accordance with accepted academic practice. No use, distribution or reproduction is permitted which does not comply with these terms. 